\title{
Visitors to two types of museums: do expenditure patterns differ?
}

\section{JuAN GABriel BRIDA, MARTA Disegna AND RAFFAElE SCUderi}

School of Economics and Management, Free University of Bolzano-Bozen, Universitätsplatz 1 -piazza Università 1, 39100 Bolzano-Bozen, Italy. E-mail: juangabriel.brida@unibz.it; marta.disegna@unibz.it; Raffaele.Scuderi@unibz.it.

(Corresponding author: Juan Gabriel Brida.)

\begin{abstract}
The authors study the determinants of the expenditure behaviour of visitors to two types of museums. Ad hoc surveys were conducted between June and September 2011 of visitors to the South Tyrol Museum of Archaeology and the Museum of Modern and Contemporaneous Art of Trento and Rovereto (MART). These are the two principal museums in the Italian provinces of Bolzano and Trento. The double-hurdle model is used via the Heien and Wessels two-step estimator. This procedure splits the process of spending decision into the stages of 'selection' and 'outcome', and also results in consistent estimates. The findings highlight two distinct profiles. The spending of visitors to the modern art museum is positively related to its cultural interest, whereas the expenditure profile of the archaeological museum visitors is more 'generalist'.
\end{abstract}

Keywords: visitors' expenditure; museums; double-hurdle model; spending behaviour

\section{C19; D12; L83}

Museums are the most popular cultural attractions (McKercher, 2004), followed by art galleries and monuments. Their unique cultural role is built on the creation of new understandings of the past and the reaffirmation of an identity in time and space (McIntosh and Prentice, 1999), which is often unavailable elsewhere (Graburn, 1983, 1998; Tufts and Milne, 1999). For a long time

This research was supported by the Autonomous Province of Bolzano project 'Le attrazioni culturali e naturali come motore dello sviluppo turistico. Un'analisi del loro impatto economico, sociale e culturale', and by the Free University of Bolzano projects 'Determinants of tourist expenditure: theory and microeconometric models' and 'Museum visitors: a comparative socio-economic analysis'. A preliminary version of this paper was presented at the at the ARWTE 2012 Conference, Advanced Research Workshop in Tourism Economics held in Coimbra, Portugal, 11-12 June and at the 2012 Conference of SIE, the Italian Society of Economists, Matera, Italy, 18-20 October. We wish to thank the anonymous referees for their comments and suggestions. 
visitors to cultural attractions have been treated as a homogeneous mass of people. The tendency in the recent literature is to consider them rather as a heterogeneous market with different characteristics, perceptions and needs (Hughes, 2002). Knowledge of the market then becomes a complex issue and it is often difficult to define the profile of the 'average' cultural visitor. This has serious implications for planners and policymakers responsible for maximizing the economic impact of cultural visits. In this context identifying the factors that most significantly influence individual expenditure is essential. Yet substantial differences in the spending levels of Italian visitors to different types of museums have already emerged in Istat (2010). The average expenditure on entrance fee and shop items at archaeological museums (€9.35) was found to be lower than that at modern art museums (€12.65). Such values may be indicative of dissimilar profiles of spenders. A question that arises from these data is whether the characteristics of the visitors of two distinct types of museums have a different influence on local economies. Identifying such differences in visitors' profiles might have a substantial effect the on promotion and communication policies of cultural attractions for both local policymakers and museum managers. Among other things, this may involve many different aspects, such as the integration with the overall tourist supply, perception of the museum's image, the management of internal spaces, proposals for new ad hoc temporary exhibitions and the arrangement of the permanent exhibits. In other words, such an analysis can offer precious indications about actions that might improve the economic benefit brought by museums.

The aim of this paper is to identify the determinants of three categories of travel expenditure of visitors to two different types of museum. These cultural attractions are located in the Trentino-South Tyrol region, Northern Italy. The South Tyrol Museum of Archaeology of Bolzano and the Museum of Modern and Contemporary Art of Trento and Rovereto (MART) are examined because of their economic and cultural relevance at both regional and international levels. Expenditure is analysed via an opportune econometric technique that allows us to treat it opportunely as a censored variable.

The literature on the determinants of tourist spending has focused on the behaviour of the visit to a whole country, destination or event. Nothing is available on museums. Improving the knowledge of how socio-demographic and economic, trip-related and psychographic factors influence an individual's expenditure pattern can be used to target high-spenders more effectively. It can also be helpful in creating greater satisfaction and long-term visitor relationships.

The paper is organized as follows. The next section briefly reviews the literature on tourist spending. The subsequent section presents the survey method and the characteristics of the visitors. We then, in the fourth section, report on the theoretical and econometric frameworks. In the penultimate section we present the empirical evidence and discuss the results. Finally, we set out our conclusions and their policy implications.

\section{Literature review}

Recently the attention of tourism literature towards the empirical analysis of 
demand has grown. The reviews of Lim (1997) and Song and Li (2008) testify to the increasing number of studies on this field and the considerable variety of methodologies that have been proposed. Contributions have focused mainly on the characteristics and determinants of macro-level data. Less attention has been paid to spending at the individual level. This was reported by the only two review papers on micro data studies that, to the best knowledge of the authors, are present in the literature. Wang and Davidson (2010) found 27 studies that used expenditure as the measure of individuals' demand for tourism. The review of Brida and Scuderi (2013) specifically focused on the use of microeconometric models and analysed 86 studies from 1977 to early 2012 where expenditure was taken as dependent variable.

The microeconometric techniques used for the study of expenditure determinants can be classified into two main groups. The smaller group is made up of contributions in which the decision of whether or not to spend was studied via a binary variable (Thrane, 2002; Mehmetoglu, 2007; Dolnicar et al, 2008; Alegre et al, 2010; Brida et al, 2012a). The larger group of studies instead analysed the level of spending overall per interviewee or standardized in terms of the per capita and/or per day amount. The use of the ordinary least squares (OLS) estimator, though very frequent, produces inconsistent and biased estimates that are related to the presence of a zero-censored dependent variable and the violation of standard assumptions (Maddala, 1983; Amemiya, 1984). The Tobit model (Tobin, 1958) is instead specifically conceived for use with censored responses (Leones et al, 1998; Downward et al, 2009; Barquet et al, 2011; Zheng and Zhang, 2011). The restrictive assumptions of the latter technique have led to its generalization through the double-hurdle approach (Cragg, 1971). This separates the spending decision into the stages of 'whether' and 'how much' to spend. This model has been used widely in different fields, such as the evaluation of public goods (Saz-Salazar and Rausell-Köster, 2008; López-Mosquera and Sánchez, 2011; Marzetti et al, 2011; Marzetti and Disegna, 2012), food expenditure (Newman and Matthews, 2001; Bai et al, 2010), analysis of consumption (Jones and Yen, 2000; Aristei and Pierani, 2008), and visitors' expenditure (Hong et al 1999; Weagley and Huh, 2004; Hong et al, 2005; Nicolau and Màs, 2005; Jang et al, 2007; Jang and Ham, 2009; Kim et al, 2010; Brida et al, 2012b, 2013).

Cragg's (1971) approach estimates a probit model for the first stage, whereas a log-normal or truncated normal model is used for the amount of spending. Residuals of the two parts are supposed to be uncorrelated. Later, Heckman (1976) proposed a more general approach that explicitly considered the possibility that the two parts were related. More recently, Heien and Wessels (1990) improved Heckman's estimator by enhancing the information from all the observations at each stage. Nevertheless only a few of contributors in the tourism field have applied this last estimator (Brida et al, 2012a, 2013).

\section{Methodology}

\section{The museums}

The research involved the two most important museums of the Trentino-South 


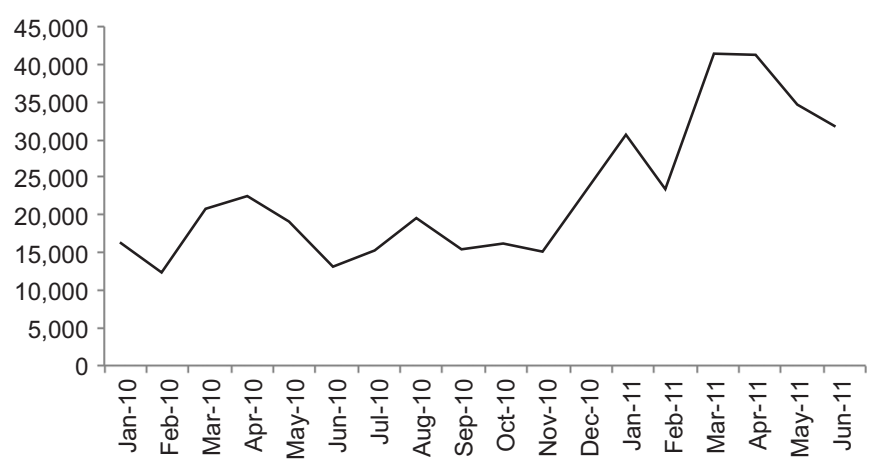

Figure 1. MART: monthly visitor flows.

Tyrol region in Northern Italy. The first is the Museum of Modern and Contemporary Art (MART), whose buildings are located in the cities of Trento and Rovereto, the two main centres of the province of Trento, Trentino. The main building is located in Rovereto, the hometown of the futurist artist Fortunato Depero, and was designed by the Swiss architect Mario Botta. MART hosts both a permanent collection, with works displayed on a rotating basis, and a temporary exhibition. It holds the most important collections in Italy for different genres of modern and contemporary art. Figure 1 reports the monthly visitor flows in this museum from January 2010 to June 2011. Although the time series is very short, the data seem to suggest an increase in the number of visits that also exhibits a seasonal pattern.

The second cultural attraction is the South Tyrol Museum of Archeology (ÖTZI) in the province of Bolzano, South Tyrol. It hosts the permanent exhibition of Ötzi, 'the iceman'. This is a mummy from the Neolithic period of a man who lived in the region more than 5,000 years ago. Ötzi was found in September 1991 on the Ötztal Alps by two German hikers. At a first sight, it was thought to be the remains of an unfortunate victim of the mountains. Later, scholars discovered that it was one of the oldest mummies in the world. Owing to its good preservation and the presence of several belongings, it is an important source for scientists investigating the living conditions of our early ancestors. The mummy can be seen by visitors through a window in the socalled 'Iceman Box', a refrigerator that keeps Ötzi at a particular temperature and in the necessary humidity. Figure 2 reports the monthly time series of the number of visitors to this museum from January 2007 to November 2010. What emerges is a different seasonal pattern from that discernible at MART, where the peaks appear during the summer months (especially between July and September).

Owing to their geographical location in a mountain region, both MART and ÖTZI are potentially more accessible mountain tourists. However, ÖTZI is located further north than MART. This makes it more accessible to Austrian and German tourists, although the same transportation lines serve Rovereto and Trento (the same highway and railway). 


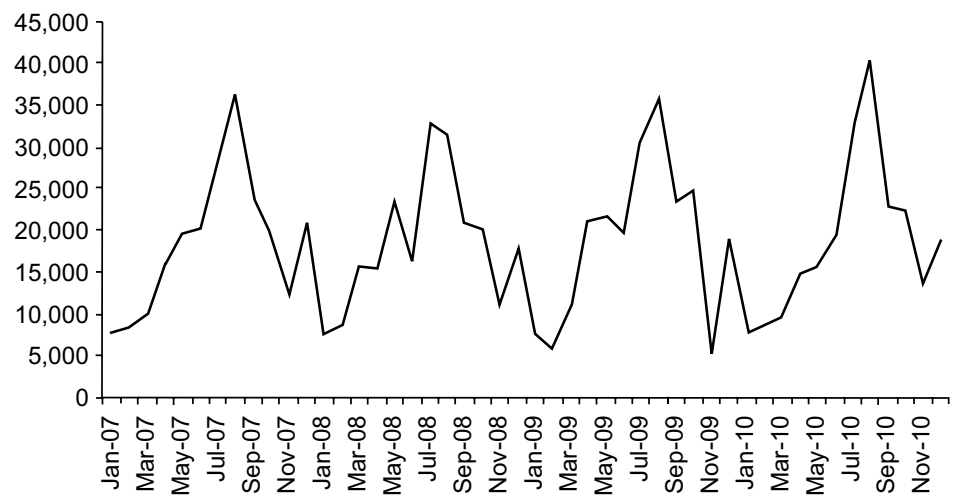

Figure 2. ÖTZI: monthly visitor flows.

\section{The questionnaire}

The survey was conducted from June to September 2011. A total of 1,288 interviews (tourists, day-visitors and local residents) was successfully collected from the two museums almost equally ( $46 \%$ for MART, $54 \%$ in the ÖTZI museum). Respondents were informed that the research had exclusively scientific aims and that impartiality in data analysis was guaranteed. Furthermore, a pilot survey was carried out to test the questionnaire before conducting the full survey. This was done to avoid biases related to the questionnaire structure and wording. Interviews were held with visitors leaving the museums after their visit on selected working and weekend days of the four months analysed, and during different periods of the day. Only one person per travel party was selected. The questionnaires were anonymous and self-administrated in three languages (Italian, German and English). A research team member was present to respond to questions or conerns. A convenience sampling method was used, as there was not enough information about the population to apply a probabilistic design. Of course, there are well known limitations in drawing inferences from a non-probability sampling, and all the related caveats apply in interpreting the empirical evidence.

The questionnaire was structured in three sections - see Table 1. The first concerned information related to the visit to the museum. The second included trip-related characteristics, whereas the third surveyed socio-economic variables such as gender, age, education, occupation and income.

\section{Visitor profiles}

Table 2 compares the profile of visitors to MART and ÖTZI. Three subgroups of visitors were analysed, corresponding to categories of spending: total, accommodation, food and beverages. This distinction will also be kept in the econometric estimates. Total expenditure includes all the items referring to a direct 'economic trace' on the visited territory: accommodation, food and beverage, pharmacy, tour guide services, purchases in the museum's shop and in other shops of the city, and other expenditure. It excludes spending on transportation, which usually benefits residents marginally. Expenditure on 
Table 1. Structure of the questionnaire.

\section{Section Object}

I

Museum information

II

III

\section{Description}

Repeat visiting; number of museums visited in the last year; push factors; ${ }^{a}$ rating of factors that describe the visit; ${ }^{b}$ shopping expenditure at the museum; authenticity perception. ${ }^{\text {a }}$

Purpose of the trip; number of nights, expenditure per night and type of accommodation used by tourists; expenditure per day for different items.

Some socio-demographic and economic characteristics of interviewees and their families.

Note: ${ }^{a}$ Dichotomous variables; ${ }^{b}$ Likert scale from 1 to 5.

Table 2. Socio-demographic and economic characteristics of visitors.

Variables

Household size

(mean)

Presence of children

$(\%)$

Origin of tourist $(\%)$

Abroad

Germany

Centre/South Italy

North-East Italy

North-West Italy

Resident

(Bolzano-Trento)

Married (\%)

Male (\%)

Age (mean)

University degree

$(\%)$

Occupation (\%)

Autonomous worker

Employed

Other occupation

Retired

Student

Household annual income (\%)

$0-25,000$

$25,000-50,000$

$51,000-75,000$

$>76,000$

Missing income
Total expenditure

Accommodation

Food and beverage MART ÖTZI $p$-value MART ÖTZI $p$-value MART ÖTZI $p$-value

Notes: $p$-value is the significance of the Chi-square test (qualitative variables), $z$-test (dichotomous variables), and $t$-test (quantitative variables). Results are not statistically significant unless indicated as: ** significant at $p \leq 0.01$ or * significant at $p \leq 0.05$. 
accommodation catches the behaviour of those who decided to spend an overnight holiday in the territory, and as such it includes only tourists. Food and beverages is the most non-discretionary expenditure item, besides accommodation, that leaves economic traces on the territory. Unlike accommodation, it includes same-day visitors and residents, in addition to tourists.

The average household size visiting the museums was greater for ÖTZI and did not differ significantly for those who spent on accommodation. This may indicate that same-day visitors to ÖTZI had larger families, which is confirmed by the higher presence of children and married people.

The distribution of the place of origin was also significantly heterogeneous. Visitors coming from abroad, and Germany in particular, are more frequent at ÖTZI. MART instead appears to attract more people from neighbouring regions. Gender differs significantly only for non-overnight visitors, whereas the gap between mean ages is never significant.

Variables measuring education and economic status provide interesting indications about the profile of visitors. MART's average visitor had a higher education than the one of ÖTZI and was more frequently a retired person or student, the latter being significant only for non-overnight visitors. The household annual income is instead higher for those who visited ÖTZI and did not stay overnight.

Earlier descriptive evidence of the spenders' profiles suggests the presence of two different types of visitor. People with higher cultural interest and residents in nearby areas visit MART more frequently. ÖTZI's audience is instead more attractive for foreigners and families with children. Often differences in the profiles do not appear to be significant for those who stay overnight.

\section{Modelling tourist expenditure}

\section{Theoretical framework}

Economic theory on tourist behaviour as consumer is usually analysed under the classical utility framework. The consumer chooses the quantities of goods and services that maximize her or his utility, given a budget constraint and a set of preferences (Papatheodorou, 2006). A basic theoretical model for studying the factors influencing the level of expenditure can be derived from Downward and Lumsdon $(2000,2003)$. If $q_{j} \mid t$ represents the quantity demanded of the commodity $j$ at time $t, p_{j}$ is the commodity's relative price, $B_{k}$ and $T_{k}$ are, respectively, consumer $k$ 's budget and tastes, demand can be seen as:

$$
q_{j} \mid t=q\left(p_{j}, B_{k}, T_{k} \mid t\right) .
$$

Considering prices explicitly provides a formulation of demand that is difficult to assess from sectional data. A more convenient representation of Equation (1) is the Engel curve:

$$
\sum_{j} p_{j} q_{j} \mid t=p q\left(B_{k}, T_{k} \mid t\right)
$$

where total expenditure is interpreted as depending from the budget and tastes. 
Empirical studies express budgetary limitations and tastes as function of measurable characteristics. Brida and Scuderi (2013) distinguish between economic constraints, socio demographic, psychographic and trip-related variables.

\section{Econometric model}

This study adopts a procedure for modelling expenditure as a zero censored variable. The double-hurdle model (Cragg, 1971) is estimated by means of the Heien and Wessels (1990) two-step estimator. The choice of this procedure is driven by the presence of a significant number of visitors that declared expenditure equal to zero. The estimation strategy of Heien and Wessels, in fact, enhances the information coming from the individuals who both spent and did not.

Each consumer is supposed to face two 'hurdles' before purchasing, which correspond to two distinct equations of 'selection' (whether or not to purchase) and 'outcome' (if they spend, how much money to allocate to that item). In Cragg's (1971) version a probit model is used for the selection stage, whereas OLS assesses the factor influencing the outcome. Cragg (1971) assumes that the residuals of the two stages are uncorrelated. Heckman (1976) generalizes this procedure by introducing a regressor in the outcome equation called the inverse Mills ratio' (MR), which is computed from the first stage via a probit model. Besides being a correction factor for the zero censoring, MR's statistical significance indicates that there have been two dependent stages in the purchasing decision process. In case MR is not significant the two stages are independent and a Tobit model can be used. Heien and Wessels (1990) improved Heckman's (1976) estimator with the use of all available observations in both stages, whereas the Heckman's (1976) second stage utilized only those units that declared positive spending.

\section{The double-hurdle model: a technical description}

Suppose that the willingness to spend of the $i$ th visitor from a set of $n$ individuals is a latent variable expressed by $y_{1 i}^{*}$. If $\mathbf{X}_{1 i}$ is a $(n \times(1+K))$ matrix reporting a column of 1 's corresponding to the intercept, and $K$ columns each corresponding to an independent variable, the linear relation of dependence of $y_{1 i}^{*}$ from $\mathbf{X}_{1 i}$, plus an error term, $v_{i}$, normally distributed with zero mean and constant variance $\left(\sigma_{1}\right)$, is expressed by:

$$
y_{1 i}^{*}=\mathbf{X}_{1 i} \beta_{1}+v_{i}
$$

where $\beta_{1}$ is a vector of $(1+K)$ coefficients to be estimated. Owing to the unobservability of the latent variable there can be defined an observable dummy variable $\left(y_{1 i}\right)$, in which each element is linked to the latent variable by means the following equation:

$$
y_{1 i}=\left\{\begin{array}{l}
1 \text { if } y_{1 i}^{*}>0 \\
0 \text { otherwise }
\end{array}\right. \text {, }
$$


that is $y_{1 i}$ equals 1 in case the consumer decides to spend. Given Equation (3), Relation (4) and the assumptions made about the error term, it can be found that the model that described the selection stage is the probit model. The probability that the $i$ th visitor will spend (Maddala, 1983) can be expressed as:

$$
P\left(y_{1 i}=1\right)=P\left(\mathbf{X}_{1 i} \beta_{1}+v_{i}>0\right)=\Phi\left(z_{i}\right),
$$

with $\Phi(\cdot)$ being the standard normal cumulative distribution, and $z_{i}=\left(\mathbf{X}_{1 i} \beta_{1}\right) /$ $\sigma_{1}$. Parameters $\beta_{1}$ are usually estimated via maximum likelihood. After estimations of the first stage inverse MR is computed as:

$$
M R_{i}=\left\{\begin{array}{ll}
\phi\left(z_{i}\right) /\left[1-\Phi\left(z_{1}\right)\right] & \text { if } y_{1 i}=1 \\
\phi\left(z_{i}\right) / \Phi\left(z_{1}\right) & \text { otherwise }
\end{array}\right. \text {, }
$$

where $\phi(\bullet)$ is the density function for a standard normal variable. The MR enters as regressor in the second 'hurdle' and corrects OLS for inconsistencies and bias in the presence of a censored variable:

$$
y_{2 i}=\mathbf{X}_{2 i} \beta_{2}+\alpha M R_{i}+\varepsilon_{i} .
$$

In Equation (7), $y_{2 i}$ is the observed amount the visitor is willing to spend; $\mathbf{X}_{2}$ is a matrix of dimension $(n \times(1+J))$, reporting a column of 1 s and a set of $J$ independent variables; $\beta_{2}$ and $\alpha$ are constant parameters; $\varepsilon_{i}$ is a random component with zero mean. In particular, $\alpha=\sigma_{12} / \sigma_{1}$, where $\sigma_{12}$ is the covariance between the error terms of the equations about the two hurdles (Heckman, 1976). If $\alpha=0$ the 'selection' stage and the 'outcome' stage are independent.

\section{Selection of regressors}

A list of candidate regressors included in the model is reported in Table 3. Income and expenditure variables are added by a dummy variable assuming the value of 1 when the respondent does not report the amount. This correction increases the sample size that would nevertheless be affected by a greater nonresponse rate. Income was surveyed in classes (Table 2) in order to increase the response rate, but in regressions models the central value of each class is considered. Two other metric variables, that is the number of nights and age, are added by their squared values in order to test for nonlinear effects.

Owing to their high number of candidate regressors a selection of them is required. In this sense guidelines can emerge from economic theory. As reported above, indications of theoretical models about the elements explaining tourist expenditure, and in particular the spending behaviour of tourists at cultural attractions, such as museums, are vague and related to generic explanatory variables, such as budgetary limitations and 'tastes'. An alternative choice could be selection on the basis of what previous regression analyses were considered. Nevertheless, as already stressed, no past contributions have studied the determinants of the spending of tourists visiting museums. Moreover, as the review of literature by Brida and Scuderi (2013) reports, studies on the 
Table 3. List of independent variables.

\section{Independent variables}

\section{Economic constraints}

Income

Missing income

Trip-related

Week end

First time

Number of museums visited

Group

Nights*

Nights $2^{*}$

Expenditure on other items

Accommodation

Missing accommodation

Transportation

Missing transportation

Food and beverage

Missing food and beverage

Shopping at the museum

Missing shopping at the museum

Timing of the visit to the museum

Psychographic

Why have you visited the museum today?

Satisfy curiosity

Rest/Relax

Specific interest

Accompany friend/family member

Learn something new

Something which one ought to do

Doing something worthwhile

Occupy some leisure time

Visit the temporary showroom

What was the main motivation for visiting this city?

Visit this museum

Visit/know the city

Accompany friends or relatives

Socio-demographic

Household size

Children

Origin

Abroad

Germany

Centre and South of Italy

North-East of Italy

North-West of Italy

$0=$ Ot.

\section{Descriptions}

The central value of each income class is considered; $0=\mathrm{NR}$ 1 = income NR; 0 = Ot.

$1=$ visit on Friday, Saturday or Sunday; $0=$ Ot.

$1=$ never been to this museum before the interview; 0 = Ot.

Number of visited museums in the last 12 months

1 = the visit is made with an organized group and/or with

friends/colleagues; $0=$ Ot.

Number of nights paid for; 0 = same-day visitor

Squared number of nights

Expenditure for accommodation; $0=\mathrm{NR}$

1 = expenditure for accommodation NR; $0=$ Ot.

Expenditure for transportation; $0=\mathrm{NR}$

1 = expenditure for transportation NR; $0=$ Ot.

Expenditure for food and beverage; $0=\mathrm{NR}$

$1=$ expenditure for transportation NR; $0=$ Ot.

Expenditure at the shop of the museum; $0=\mathrm{NR}$

$1=$ expenditure at the shop NR; $0=$ Ot.

$1=$ the respondent visited the museum before the city;

$1=$ Satisfying curiosity; $0=$ Ot.

$1=$ Relaxing; 0 = Ot.

$1=$ Specific interest in such an attraction; $0=$ Ot.

$1=$ Specific interest of a friend/family member in such an attraction; $0=$ Ot.

$1=$ Learning something new; $0=$ Ot.

$1=$ Something which one ought to do; $0=$ Ot.

$1=$ Doing something worthwhile; $0=$ Ot.

1 = Occupying some leisure time; $0=$ Ot.

$1=$ Visiting the temporary showroom; $0=$ Ot.

$1=$ Visiting this museum; $0=$ Ot.

$1=$ Visiting or knowing the city; $0=$ Ot.

$1=$ Accompanying or visiting friends or relatives; $0=$ Ot.

Number of members of the family

$1=$ presence of children under $13 ; 0=$ Ot.

1 = foreign country, excluding Germany; 0 = Ot.

(reference category for accommodation where residents are excluded)

$1=$ Germany; 0 = Ot.

$1=$ province in Centre or South of Italy; $0=$ Ot.

$1=$ province in North-East of Italy (excluding the province

in which the museum is located); $0=$ Ot.

$1=$ province in North-West of Italy; $0=$ Ot. 
Table 3 continued.

Independent variables

Resident

Male

Age

Age2

Education

University

Occupation

Self-employed

Employed

Retired

Student

Other

Married

$M R$

\section{Descriptions}

$1=$ respondent resides in the province in which the museum is located (Trento for MART, Bolzano for ÖTZI); 0 = Ot.

(reference category for total expenditure and food and beverage expenditure models)

1 = male; 0 = female

Age of the respondent

Age squared

$1=$ university degree or postgraduate; $0=$ Ot.

$1=$ self-employed; $0=$ Ot.

1 = employed, full-time or part-time; $0=$ Ot.

$1=$ retired; $0=$ Ot.

1 = student; 0 = Ot. (reference category)

1 = unemployed/housewife/working occasionally or on project/ other; 0 = Ot.

$1=$ married; $0=$ Ot.

Inverse Mills Ratio

Notes: "This variable was taken into consideration only for MART museum due to the large number of missing in ÖTZI dataset. NR = Not Reported; Ot. = Otherwise

determinants of tourist consumption use a high number of heterogeneous regressors. Of course, such heterogeneity can also be related to the absence of a robust theoretical framework in guiding the selection of indicators. Brida and Scuderi (2013) grouped all used regressors into categories that were used as guidelines to select the regressors reported by Table 3 .

In this paper, for all these reasons, the choice is directed by a statistical criterion. In particular, identification is made through a backward stepwise analysis at each 'hurdle' of the model. Stepwise analysis selected those regressors that were significant at a level less than 0.05 . Such an approach has the advantage that it operates a choice among the regressors on the basis of an optimality criterion. The main negative aspect concerns the difficulty in comparing estimated coefficients if different regressors are selected for each museum. This may affect the objective of evaluating the intensity of coefficients between models, but it allows for a qualitative comparison between those elements that emerge as most significant. Moreover, the use of stepwise might sometimes appear to be a merely mechanical selection of regressors, as also stressed by Brida and Scuderi (2013). However, in a field where no robust theoretical indications emerge about the selection of regressors, this appears to be the most reasonable criterion for characterizing the significant spending profile of each museum's visitors. Of course, future research would greatly benefit from relevant theoretical works on the economics of cultural visitors. 
Table 4. Determinants of total expenditure per capita per day (excluding transportation).

\begin{tabular}{|c|c|c|c|c|}
\hline \multirow[b]{2}{*}{ Independent variables } & \multicolumn{2}{|c|}{ MART } & \multicolumn{2}{|c|}{ ÖTZI } \\
\hline & $\begin{array}{l}\text { First } \\
\text { stage }^{* \mathrm{M}}\end{array}$ & $\begin{array}{l}\text { Second } \\
\text { stage }^{* * \mathrm{M}}\end{array}$ & $\begin{array}{l}\text { First } \\
\text { stage }^{* \mathrm{~S}}\end{array}$ & $\begin{array}{l}\text { Second } \\
\text { stage }^{* * \mathrm{~S}}\end{array}$ \\
\hline
\end{tabular}

Economic constraints

Income

Missing income

$0.231(0.04)$

Trip-related

Weekend

$-0.659(0.12)$

First time

$0.292(0.12)$

$0.380(0.15)$

Number of museums visited

$0.842(0.24)$

Timing of the visit to the

museum

$0.391(0.17)$

Psychographic

Why have you visited the museum today?

Specific interest

$\begin{array}{lrr}\text { Learn something new } & 0.428(0.14) & 11.060(3.05) \\ \text { Doing something worthwhile } & -0.338(0.15) & -10.777(2.66)\end{array}$

$4.981(2.52)$

What is the main motivation for visiting this city?

Visit this museum

$-0.274(0.12) \quad-8.074(2.56)$

Accompany friends or relatives

$-6.871(2.77)$

Socio-demographic

Origin

Abroad

$1.473(0.39)$

$62.475(9.86)$

$2.088(0.38)$

$62.910(6.42)$

Germany

$1.328(0.36)$

$35.368(5.79)$

$1.947(0.36)$

$52.828(5.37)$

Centre and South of Italy

$1.091(0.23)$

$40.240(4.52)$

$2.172(0.38)$

$58.986(6.81)$

North-East of Italy

$0.338(0.14)$

$19.583(2.43)$

$1.679(0.38) \quad 51.237(5.88)$

North-West of Italy

$0.799(0.19)$

$35.702(4.65)$

$1.780(0.37) \quad 54.081(5.73)$

University

Married

$0.352(0.11)$

$5.565(2.38)$

Household size

$6.816(2.96)$

$M R$

Constant

$-0.802(0.17)$

$16.445(2.82)-1.244(0.35)$

$27.254(5.7)$

Notes: Robust SE in parentheses. ${ }^{* \mathrm{M}}$ Number of obs $=590 ;$ Wald $\mathrm{chi}^{2}(9)=82.14 ; \mathrm{Prob}>\mathrm{chi}^{2}=0 ; \mathrm{Log}$ pseudolikelihood $=-357.5794$; McKelvey and Zavoina's $R^{2}=0.223 ;{ }^{* * \mathrm{M}}$ Number of obs $=590$; $F(12,577)=16.87$; Prob $>F=0$; Adjusted $R^{2}=0.271 ;{ }^{*}$ Number of obs $=650$; Wald $\operatorname{chi}^{2}(9)=88.05$; Prob $>\mathrm{chi}^{2}=0$; Log pseudolikelihood $=-322.29457 ;$ McKelvey and Zavoina's $R^{2}=0.248 ;{ }^{* *}$ Number of obs $=650 ; F(11,638)=37.97 ;$ Prob $>F=0 ;$ Adjusted $R^{2}=0.408$.

\section{Results}

Tables 4,5 and 6 report the results from a stepwise selection of the estimated robust (White, 1980) double-hurdle models. In particular, Table 4 reports the selected variables for total expenditure, separately for the two museums. Tables 5 and 6 present the results for accommodation and food and beverages for MART and ÖTZI, respectively. The MR is not significant only in explaining the behaviour of food and beverages spending of MART visitors. This indicates that the two stages of 'selection' and 'outcome' are independent and that the 
use of a Tobit model is necessary. The significance of MR for the other models suggests instead that the two-stage approach is appropriate.

\section{Total expenditure}

A positive influence on the probability of spending for MART visitors emerges from those who had a primary interest in the museum and decided to visit it before going to the city (Table 4). Variables affecting only the level of expenditure are the number of museums visited in the past 12 months and the high level of education of the visitor, both having positive signs. A negative influence emerges among those who decided to visit the city only to accompany a friend or a relative. The rest of significant variables affect both the 'selection' and 'outcome' levels. These concern those who visited the museum in order to learn something new, married visitors and residents outside the province, all being in a positive relationship with spending. Among non-residents the greatest impact on the level of spending is given by those who live in foreign countries other than Germany, followed by those living in the Centre-South of Italy. Instead 'generalist' visitors, those whose motivation for visiting is 'doing something worthwhile', show negative coefficients for both the decision and level of spending.

A negative association with those who did not declare their income affects the probability of spending for ÖTZI visitors. This indicates that those who omitted their wealth status decided to spend less frequently. The probability of spending is instead higher for weekend visitors and first-time visitors. The level of total purchases is positively influenced by income and declaring a specific interest in visiting ÖTZI, whereas those who visited the temporary showroom and came with a high number of household members spent a lower amount. Factors influencing both stages are instead the decision to visit the museum as main motivation to come to Bolzano and the origin of visitors, the former having a negative effect on spending. Similarly to MART, the spending of visitors is higher for residents in foreign countries other than Germany and the Centre-South of Italy, meaning that the higher the distance, the higher the willingness to spend.

\section{Expenditure on accommodation and food and beverages: MART}

The decision to spend on accommodation facilities measures the cost of choosing to stay overnight. For MART visitors, income, visit during the weekends and number of nights are significant drivers in the decision on whether or not to commit to an overnight stay (Table 5). In particular, non-linear effects of the number of nights are found, in terms of a less than proportional effect on spending. All these variables do not influence the amount of money spent.

Party size has instead a negative role in the decision on whether to stay overnight. The results also show that those who stay overnight visit the museum as one of the attractions of the city, and accordingly think that visiting the museum is something one ought to do. The probability of spending on accommodation facilities is positively related to spending on transportation, food and beverages, and, of course, to living outside the province, whereas married visitors are likely to decide to spend less frequently. 


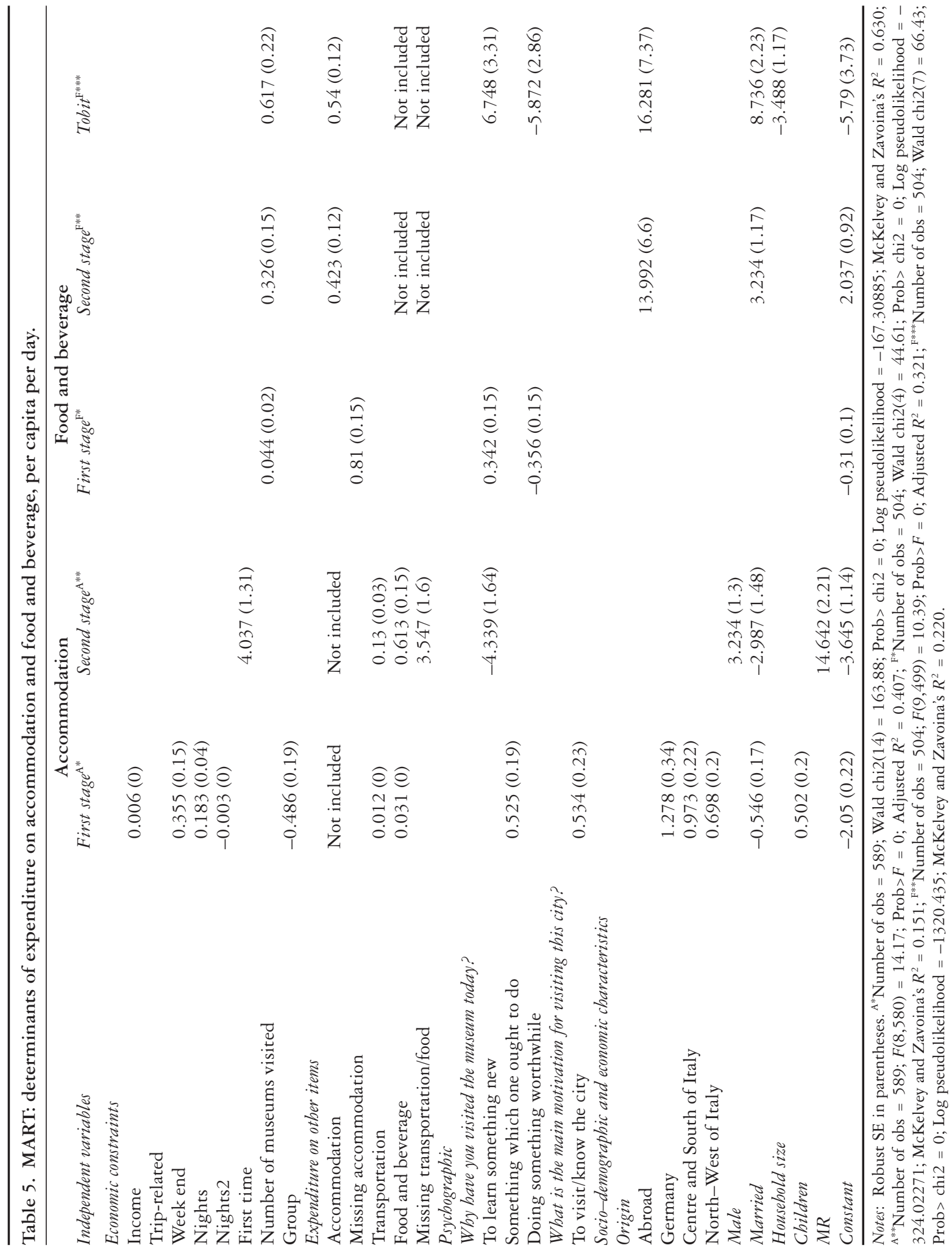


The amount of expenditure on accommodation appears to be positively associated with the first-time visit, spending on transportation, food and beverages, and male respondents. Those who declare that museum is a chance to learn something new are in an inverse relationship with spending, as well as married respondents. The origin of visitors was not significant in discriminating the decision on the amount to allocate on this item, whereas it influences the decision on whether to spend on an overnight stay. With respect to foreign tourists, those living in the North-East of Italy (the closest area) are not significant for accommodation as expected.

As observed before, the expenditure on food and beverages of MART visitors was examined through the Tobit model. Regarding the determinants of this kind of expenditure, there emerge positive relationships with the number of museums visited, married visitors, spending on accommodation facilities, and those declaring that the visit is a chance to learn something new. Negative relationships are found with household size and the generalist opinion that visiting MART is worthwhile. The only significant category of visitors with regard to origin is that of the visitors who come from a foreign country other than Germany.

\section{Expenditure on accommodation, and food and beverage: ÖTZI}

Similar to total expenditure, the decision of spending on both accommodation and food and beverages for ÖTZI visitors is negatively associated with the omission of income on the questionnaires (Table 6). The decision of paying for accommodation is also negatively related with the number of museums visited. Variables positively affecting the decision on an overnight stay are spending on food and beverages, willingness to visit the city, age and residence in Germany and the Centre-South of Italy with respect to those living in other foreign countries. The amount of spending in accommodation facilities is positively associated with income, spending on food and beverages, willingness to visit the city and age. Negative factors influencing to that expenditure are the number of museums visited in the last year, shopping at the museum and household size.

The probability of spending on food is higher for first-time visitors and those who spent on transportation. An inverse relationship emerges from those who aim to visit both the museum and the city as the main activity of their trip, and autonomous workers. The level of expenditure is positively related to income level, group size and specific interest in visiting ÖTZI. A negative coefficient is found in relation to both the museum visit and knowledge of the city as the main motivations for the trip, residence in the North of Italy and household size.

\section{Discussion}

The empirical evidence suggests two distinct spending behaviours between the visitors to the two museums. What emerges also reflects the different roles of the two attractions that need to be taken into account when determining an economic impact for the two cities. Of course, a comprehensive discussion 
Table 6. ÖTZI: determinants of expenditure on accommodation and food and beverage, per capita per day.

Independent variables

\section{Accommodation}

$\begin{array}{ll}\text { First } & \text { Second } \\ \text { stage }^{\mathrm{A}^{*}} & \text { stage }\end{array}$

Economic constraints

Income

Missing income

Trip-related

First time

Number of museums visited

Group

Expenditure on other items

Missing accommodation

Transportation

Food and beverage

Missing transportation/food

Shopping at the museum

Psychographic

Why have you visited the museum today?

Specific interest

What is the main motivation for visiting this city?

To visit this museum

To visit/know the city

Socio-demographic

Origin

Germany

Centre and South of Italy

North-East of Italy

North-West of Italy

Household size

Occupation

Autonomous worker

Retired

Age

$M R$

$$
\begin{array}{rr}
0.025(0.01) & 0.276(0.07) \\
-0.553(0.16) & -8.657(3.79) \\
& -0.125(0.05)
\end{array}
$$

$-0.586(0.13)$

$$
0.136(0.03)
$$

$0.339(0.16)$

$6.005(2.41)$

$$
\begin{array}{ll}
0.637(0.12) & 6.824(1.25) \\
0.076(0.03) &
\end{array}
$$

$0.08(0.02)$

$2.682(1.23)$

$-0.473(0.14)-6.332(1.71)$

$$
0.334(0.11) \quad 6.263(2.03)-0.322(0.14)-5.086(1.78)
$$

$0.403(0.16)$

$-3.903(1.04)$

$-2.936(0.62)$

$-0.379(0.14)$

$0.012(0)$

$0.323(0.09)$ $-24.877(3.12)$

Constant

$-0.484(0.23)$

Notes: Robust SE in parentheses. ${ }^{A *}$ Number of obs $=647$; Wald chi2 $(8)=90.54 ;$ Prob $>$ chi2 $=0$; Log pseudolikelihood $=-380.04211 ;$ McKelvey and Zavoina's $R^{2}=0.282 ;{ }^{A^{* *}}$ Number of obs $=647$; $F(9,637)=20.99 ;$ Prob $>F=0 ;$ Adjusted $R^{2}=0.238 ;{ }^{\mathrm{F} *}$ Number of obs $=555 ;$ Wald $\operatorname{chi} 2(7)=77.44$; Prob $>$ chi2 $=0 ;$ Log pseudolikelihood $=-328.88707 ;$ McKelvey and Zavoina's $R^{2}=0.300 ;{ }^{\text {F** Number }}$ of obs $=555 ; F(10,544)=13.47 ;$ Prob $>F=0 ;$ Adjusted $R^{2}=0.230$.

about the economic flows generated by museums for local communities is a complex issue. Trips are often taken for different purposes, and the cultural aspect and the visit to a museum will sometimes be just one feature. Accordingly, one has to find proper measures to 'allocate' expenditure to each single purpose. Therefore, in the case of multi-purpose trips it is very reductive to relate the presence of a tourist in a museum directly to his or her overall 
economic trace in the territory. However, the frequent and significant presence of certain elements in explaining both the decision to spend and the amount of the expenditure can provide precious information. This can help in determining ad hoc promotion and marketing communication strategies for both museums and territories. These strategies can stimulate actions in which the aim of the museums' managers to attract visitors merges with the aim of local policymakers to obtain the highest economic returns to the community.

The different pictures that emerge of the two museums also highlight their different roles in their cities, because of their different nature and the resultant communication and promotion campaigns that attract different types of visitor. However, the difference also relates to their location in neighbouring areas that are nevertheless characterized by distinct cultural influences (German in South Tyrol and Italian in Trentino) and accessibility from adjoining locations.

Overall MART appears to be a very important attractor for tourism in Rovereto also from an economic point of view. Such importance is reflected in the significant positive 'activation' of the decision to spend by those who visit the museum before the city. The amount of spending is positively related to a high cultural profile, indicated by the positive sign of the number of museums visited, high level of education, and an interest in visiting the museum to learn something new. The importance of the cultural level is reinforced by the fact that the expenditure activation is inversely related to the 'generalist' visitor who goes to the museum to do something worthwhile and to accompany friends or relatives. The overall economic impact is also shown to increase with the distance from the place of residence.

Expenditure on accommodation for MART visitors seems to be related to a 'broadly touristic' profile of traveller. This is expected, for it is likely that tourists who decide to spend money on accommodation facilities are also willing to undertake different activities. In contrast, and similarly to the total amount, expenditure on food and beverage is likely to be positively associated with the profile of a visitor with 'cultural' interests.

The overall impact of ÖTZI on the local economy is associated with a more 'generalist' visitor profile. Unlike MART, positive and significant income effects on expenditure can be found in all regressions. This should stimulate efforts to attract visitors with a higher income level who are likely to spend more in the territories. With regard to total spending, important economic influences come from those who have a specific interest in the museum with no significant aim of learning something new, and who come from abroad. It has to be noted that the visitor who comes to the city only to visit the museum spends significantly less. All this leads us to think of the museum as an attraction that generates economic effects inasmuch as it is part of the local tourist supply. The pronounced seasonality of visitor flows that follows that of arrivals seems to confirm this. Overall, the contention of the ÖTZI museum as an attraction for a mass audience is supportedby the descriptive statistics, which show that it attracts families with children more frequently than MART.

The determinants of expenditure on accommodation of ÖTZI visitors recall the same profile as for visitors to MART. In addition, an age effect emerges, jointly with a low intention to attend other museums and negative household size effects. Finally, the amount spent on food and beverages also recalls the profile of a generalist visitor, as for total expenditure. In addition there is a 
negative influence from those who came mainly to visit the city or the museum in particular. This reinforces the idea of the visit to the museum and to the city of Bolzano as two complementary and necessary parts of the supply. In this context the visitor who comes to the city only to undertake a single activity is likely to have a negative effect on the economic trace left on the territory.

\section{Conclusion}

Museums are important tourist attractions. At the same time their role in the local community goes beyond that of a mere attraction for those who take an overnight holiday. The presence of a museum can constitute a meaningful value added for residents in that it increases their cultural capital. Museum visitors are also potential consumers, and as such may generate positive economic effects for local economies. Understanding the profile of visitors as spenders can inform the positioning of museums within the tourist supply of a community, and their role in determining economic flows. The objective of this research was to ascertain the different determinants of travel expenditure behaviour in two different types of museums located in the same region, both potential attractions for mountain tourists. The analysis considered three different categories of expenditure. Total spending, excluding transportation, reflects the 'economic trace' the tourist leaves on the visited community. Accommodation expenditure characterizes tourists and their decision on an overnight stay. Finally, the expenditure on food and beverages was considered since most visitors spend on this category of non-discretionary good. The use of an opportune econometric modelling was necessary to avoid the inconsistency and bias of classical OLS estimates. A generalized version of double-hurdle modelling as proposed by Heien and Wessels (1990) was then applied.

What emerged indicates the need for managers of the cultural attractions and other local policymakers to work together. If the former seek to attract visitors, the latter benefit from the spillover effect of the cultural visit. Undoubtedly, especially for many visitors who stay overnight, the cultural aspect can only be a part of a multi-purpose trip. In this sense, assessing the exact economic impact of museums on a territory is a non-trivial question. This work adopted a different perspective, since it tried to catch those elements that influence the economic trace that cultural visitors leave outside the museum.

The analysis highlighted two different ways of deriving the economic impact on local economies. The total and food and beverages expenditures of MART visitors are significantly related to a 'cultural' profile. Attracting this particular kind of visitor involves organizing high-quality events and exhibitions. In addition, an integrated supply of culture, history, nature and transportation can motivate them to stay overnight and spend on accommodation. The key visitor category to attract to ÖTZI is instead more 'generalist', wealthier and seems to be motivated by the curiosity to visit a unique attraction in the world rather than seeking its cultural aspect. Also for this museum, an integrated supply of several types of tourist attractors can be of help in enhancing the economic impact. For this second museum, we also found that income explained expenditure significantly and positively. This could be an argument for the promotion of a tourist supply that attracts the wealthier segments. 
Undoubtedly, the main effort of event managers of a museum should be addressed at making exhibitions attractive enough to catch the attention of both foreign visitors and local residents, and to keep doing so even after the first rush of interest. In this context, the difficulty lies not in generating the initial attraction but in assuring a high degree of interest and strong visitor flows over the years, in balance with the warranted investment. This issue is of particular importance for both museums, and relates both to the promotion of opportune communication strategies and to the 'revitalization' of the museum as a product. In this latter sense, museums have a great opportunity to 'renew' themselves. Their own collections can be kept attractive to the public by periodically alternating the holdings that are exhibited with those that are stored. Temporary exhibitions are another means of attracting an increasing number of visitors, both first-time and repeat visitors. In both cases, in the time of the experience economy, event culture and omnipresent place marketing, the promotion of and ongoing communication about the museum's exhibitions should become a major element of its overall public and private management strategy. Attracting people by stimulating their cultural interest in modern art or their curiosity in seeing how ancient people lived has profound implications not only for museums' ticket counters, but also for the economy of their region. This research suggests some directions in which communications should be oriented. For both museums, increased attention to the cultural aspects of exhibitions and activities and a proper promotion of their cultural value may boost their economic impact. MART seems already to be an attractor of the culturally interested' tourist who leaves an important economic trace on the territory. Perhaps ÖTZI should promote more strongly the important cultural aspects of the visitor's 'discovery' of Neolithic life. At the same time, appropriate policies should be formulated for the segment of those overnight visitors who consider the museum as 'one of the available attractions' of the city.

A specific mention should be made of temporary exhibitions. The majority of the visitors (91\% for MART, 65\% for ÖTZI) were drawn to visit because of them. This variable was found to be significant only for total expenditure associated with ÖTZI and with a negative sign. This might be an indication of a 'hit and run' behaviour, which was unlikely to be significant in explaining the decision and the level of the economic trace. When it was significant, rather, it lowered the average amount spent. Proposing, for instance, integrated tourist packages of different and related cultural events could encourage same-day visitors to stay overnight. Working on the quality of the temporary exhibition could also be useful in this respect. Interesting indications were noted by Brida et al (2012b), who found that temporary exhibition spaces were significantly perceived as authentic only for MART visitors, and not for ÖTZI. That paper stressed that 'the type of exhibition hosted by the museum can be of great importance for curators and managers in order to increase the perception of authenticity of the attraction' (Brida et al, 2012b, p 8). A survey of tourists' proposals for the improvement of such aspects would provide valuable information that was not caught by the questionnaire used in this paper, and thus it should be analysed in future research. Further research might also concentrate on the influence of multi-purpose trips and on estimating the effect of single activities or 'purposes' on the 'economic trace'. In addition, one limitation of this study is that expenditure patterns are analysed separately for each type of spending, 
rather than in an integrated way. Future research might then consider the consumer's decision-making process in a more complex manner; examining whether the choice to spend a given amount of money on one activity can influence the amount of money that the visitor is willing to pay for another activity. Interesting suggestions in this regard can be found in the work of Zhang et al (2012) and their quantitative integrated modelling of tourism behaviour.

\section{References}

Alegre, J., Mateo, S., and Pou, L. (2010), 'An analysis of households' appraisal of their budget constraints for potential participation in tourism', Tourism Management, Vol 31, No 1, pp 4556.

Amemiya, T. (1984), 'Tobit models: a survey', Journal of Econometrics, Vol 24, No 1, pp 3-26.

Aristei, D., and Pierani, L. (2008), 'A double-hurdle approach to modelling tobacco consumption in Italy', Journal of Applied Economics, Vol 40, pp 2463-2476.

Bai, J., Wahl, T.I., Lohmar, B.T., and Jikun, H. (2010), 'Food away from home in Beijing: effects of wealth, time and "free"meals', China Economic Review, Vol 21, pp 432-441.

Barquet, A., Brida, J.G., Osti, L., and Schubert, S. (2011), 'An analysis of tourists' expenditure on winter sports events through the Tobit censorate model', Tourism Economics, Vol 17, No 6, pp 1197-1217.

Brida, J.G., and Scuderi, R. (2013), 'Determinants of tourist expenditure: a review of microeconometric models', Tourism Management Perspectives, Vol 6, pp 28-40.

Brida, J.G., Bukstein, D., Garrido, N., and Tealde, E. (2012a), 'Cruise passengers' expenditure in the Caribbean port of call of Cartagena de Indias: a cross-section data analysis', Tourism Economics, Vol 18, No 2, pp 431-447.

Brida, J.G., Disegna, M., and Scuderi, R. (2012b), 'The visitors' perception of authenticity at the museums: archaeology versus modern art', Current Issue in Tourism, DOI: 10.1080/ 13683500.2012 .742042 .

Brida, J.G., Disegna, M., and Osti, L. (2013), 'Visitors' expenditure behaviour at cultural events: the case of Christmas markets', Tourism Economics, Vol 19, No 5, pp 1169-1192.

Cragg, J.G. (1971), 'Some statistical models for limited dependent variables with application to the demand for durable goods', Econometrica, Vol 39, No 5, pp 829-844.

Dolnicar, S., Crouch, G.I., Devinney, T., Huybers, T., Louviere, J.J., and Oppewal, H. (2008), 'Tourism and discretionary income allocation. Heterogeneity among households', Tourism Management, Vol 29, No 1, pp 44-52.

Downward, P., and Lumsdon, L. (2000), 'The demand for day-visits: an analysis of visitor spending', Tourism Economics, Vol 6, No 3, pp 251-261.

Downward, P., and Lumsdon, L. (2003), 'Beyond the demand for day-visits: an analysis of visitor spending', Tourism Economics, Vol 9, No 1, pp 67-76.

Downward, P., Lumsdon, L., and Weston, R. (2009), 'Visitor expenditure: the case of cycle recreation and tourism', Journal of Sport \& Tourism, Vol 14, No 1, pp 25-42.

Graburn, N.H.H. (1983), 'The antropology of tourism', Annals of Tourism Research, Vol 10, No 1, pp 9-33.

Graburn, N. (1998), 'A quest for identity', Museum International, Vol 50, No 3, pp 13-18.

Heckman, J.J. (1976), 'Sample selection bias as a specification error', Econometrica, Vol 47, No 1, pp 153-161.

Heien, D., and Wessels, C. (1990), 'Demand system estimation with micro data: a censored regression approach', Journal of Business \& Economic Statistics, Vol 8, No 3, pp 356-371.

Hong, G.S., Fan, J.X., Palmer, L., and Bhargava, V. (2005), 'Leisure travel expenditure patterns by family life cycle stages', Journal of Travel E Tourism Marketing, Vol 18, No 2, pp 15-30.

Hong, G.S., Kim, S.Y., and Lee, J. (1999), 'Travel expenditure patterns of elderly households in the US', Tourism Recreation Research, Vol 24, No 1, pp 43-52.

Hughes, H.L. (2002), 'Culture and tourism: a framework for further analysis', Managing Leisure, Vol 7, No 3, pp 164-175.

Istat (2010), 'I musei e gliistitutisimilari non statali' (http://www3.istat.it/dati/catalogo/20110524_00, accessed 15 March 2012). 
Jang, S.C.S., and Ham, S. (2009), 'A double-hurdle analysis of travel expenditure: baby boomer seniors versus older seniors', Tourism Management, Vol 30, No 3, pp 372-380.

Jang, S.C.S., Ham, S., and Hong, G.S. (2007), 'Food-away-from-home expenditure of senior household in the United States: a double-hurdle approach', Journal of Hospitality E Tourism Research, Vol 31, No 2, pp 147-167.

Jones, A.M., and Yen, S.T. (2000), 'A Box-Cox double-hurdle model', The Manchester School, Vol 68, No 2, pp 203-221.

Kim, S.S., Prideaux, B., and Chon, K. (2010), 'A comparison of results of three statistical methods to understand the determinants of festival participants' expenditures', International Journal of Hospitality Management, Vol 29, pp 297-307.

Leones, J., Colby, B., and Crandall, K. (1998), 'Tracking expenditures of the elusive nature tourists of Southeastern Arisona', Journal of Travel Research, Vol 36, No 3, pp 56-64.

Lim, C. (1997), 'Review of international tourism demand models', Annals of Tourism Research, Vol 24, No 4, pp 835-849.

López-Mosquera, N., and Sánchez, M. (2011), 'The influence of personal values in the economicuse valuation of peri-urban green spaces: an application of the means-end chain theory', Tourism Management, Vol 32, pp 875-889.

Maddala, G.S. (1983), Limited-Dependent and Qualitative Variables in Econometrics, Cambridge University Press, Cambridge.

Marzetti, S., and Disegna, M. (2012), 'Demand for the quality conservation of Venice, Italy, according to different nationalities', Tourism Economics, Vol 18, No 5, pp 1019-1050.

Marzetti, S., Disegna, M., Villani, G., and Speranza, M. (2011), 'Conservation and recreational valuesfrom semi-natural grasslands for visitors to two Italian parks', Journal of Environmental Planning and Management, Vol 54, No 2, pp 169-191.

McIntosh, A.J., and Prentice, R. (1999), 'Affirming authenticity: consuming cultural heritage', Annals of Tourism Research, Vol 26, No 3, pp 589-612.

McKercher, B. (2004), 'A comparative study of international cultural tourists', Journal of Hospitality and Tourism Management, Vol 11, No 2, pp 95-107.

Mehmetoglu, M. (2007), 'Nature-based tourists: the relationship between their trip expenditures and activities', Journal of Sustainable Tourism, Vol 15, No 2, pp 200-215.

Newman, C.M.H., and Matthews, A. (2001), 'Infrequency of purchase and double-hurdle models of Irish households' meat expenditure', European Review of Agricultural Economics, Vol 28, No 4, pp 393-419.

Nicolau, J.L., and Más, F.J. (2005), 'Heckit modelling of tourist expenditure: evidence from Spain', International Journal of Service Industry Management, Vol 16, No 3, pp 271-293.

Papatheodorou, A. (2006), 'Microfoundations of tourist choice', in Dwyer, L., and Forsyth, P., eds, International Handbook on the Economics of Tourism, Edward Elgar Publishing, Cheltenham, pp 7388.

Saz-Salazar, S., and Rausell-Köster, P. (2008), 'A double-hurdle model of urban green areas valuation: dealing with zero responses', Landscape and Urban Planning, Vol 84, pp 241-251.

Song, H., and Li, G. (2008), 'Tourism demand modelling and forecasting - a review of recent research', Tourism Management, Vol 29, No 2, pp 203-220.

Thrane, C. (2002), 'Jazz festival visitors and their expenditures: linking spending patterns to musical interest', Journal of Travel Research, Vol 40, No 3, pp 281-286.

Tobin, J. (1958), 'Estimation of relationships for limited dependent variables', Econometrica, Vol 26, No 1, pp 24-36.

Tufts, S., and Milne, S. (1999), 'Museums: a supply-side perspective', Annals of Tourism Research, Vol 26, No 3, pp 613-631.

Wang Y., and Davidson M.C.G. (2010), 'A review of micro-analyses of tourist expenditure', Current Issues in Tourism, Vol 13, No 6, pp 507-524.

Weagley, R.O., and Huh, E. (2004), 'Leisure expenditures of retired and near-retired households', Journal of Leisure Research, Vol 36, No 1, pp 101-127.

White, H. (1980), 'A heteroskedasticity-consistent covariance matrix estimator and a direct test for heteroskedasticity', Econometrica, Vol 48, No 4, pp 817-838.

Zhang, H., Zhang, J., and Kuwano, M. (2012), 'An integrated model of tourists' time use and expenditure behaviour with self-selection based on a fully nested Archimedean copula function', Tourism Management, Vol 33, No 6, pp 1562-1573.

Zheng. B., and Zhang, Y. (2011), 'Household expenditures for leisure tourism in the USA, 1996 and 2006', International Journal of Tourism Research, DOI 10.1002/jtr.880. 